\title{
Corrigendum: Ready for kindergarten: Are intelligence skills enough?
}

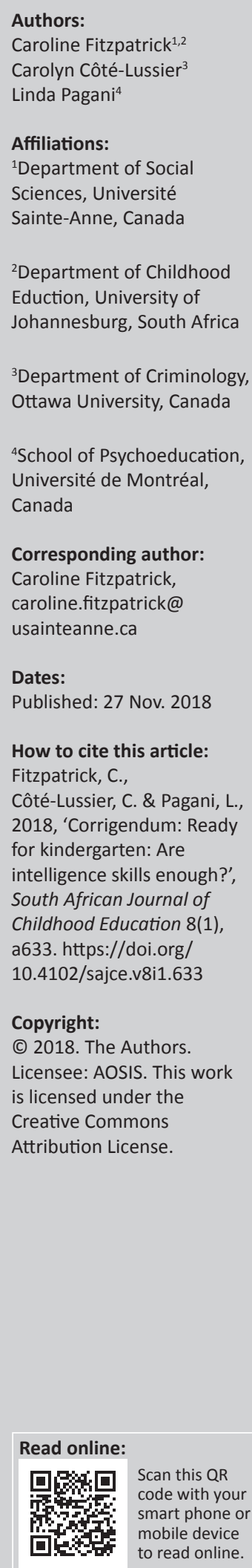

Scan this $Q R$ code with your smart phone or mobile device to read online.

In the version of this article initially published, the second and third author's names were omitted from the publication. The first author's second affiliation was also omitted. The author list, authors affiliations, and the authors' contribution section are hereby corrected to:

\section{Authors}

Caroline Fitzpatrick ${ }^{1,2}$

Carolyn Côté-Lussier ${ }^{3}$

Linda Pagani ${ }^{4}$

\section{Affiliations}

${ }^{1}$ Department of Social Sciences, Université Sainte-Anne, Canada

${ }^{2}$ Department of Childhood Education, University of Johannesburg, South Africa

${ }^{3}$ Department of Criminology, Ottawa University, Canada

${ }^{4}$ School of Psychoeducation, Université de Montréal, Canada

\section{Authors' contributions}

C.F. designed the study, conducted analyses and drafted the article. As senior author, L.P. contributed to the conceptualisation and design of the study from the onset. L.P. also provided feedback during the drafting of the manuscript and gave critical feedback during the editing process. C.C.-L. conducted analyses for the study and drafted the results section. C.C.-L. also contributed to the interpretation of the results and provided critical feedback on the entire manuscript during the editing process.

The errors have been corrected in the PDF version of the article. The author, Caroline Fitzpatrick, apologise for any inconvenience that this omission may have caused. 


\section{Ready for kindergarten: Are intelligence skills enough?}

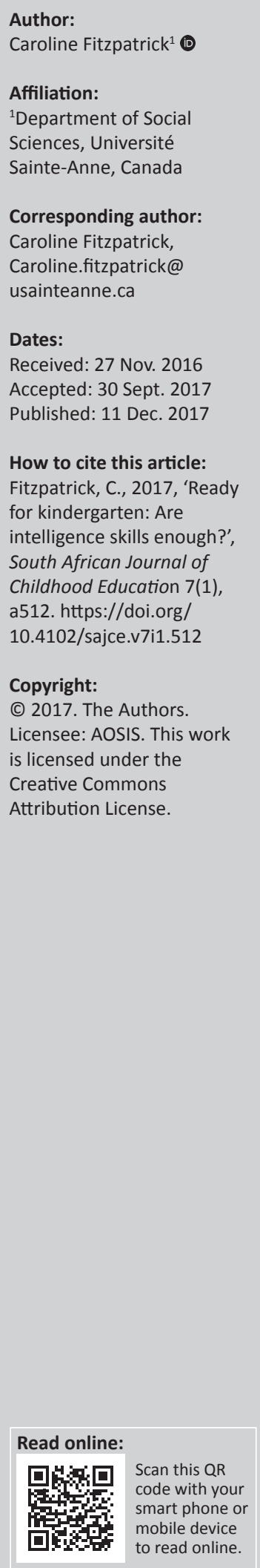

This study investigated how different profiles of kindergarten readiness in terms of student intellectual ability, academic skills and classroom engagement relate to future academic performance. Participants are French-Canadian children followed in the context of the Quebec Longitudinal Study of Child Development $(N=670)$. Trained examiners measured number knowledge, receptive vocabulary and fluid intelligence when children were in kindergarten. Teachers rated kindergarten classroom engagement. Outcomes included fourth-grade teacherrated achievement and directly assessed mathematical skills. Latent class analyses revealed three kindergarten readiness profiles: high (57\%), moderate (34\%) and low $(9.3 \%)$ readiness. Using multiple regression, we found that a more favourable kindergarten profile predicted better fourth-grade academic performance. Identifying children at risk of academic difficulty is an important step for preventing underachievement and dropout. These results suggest the importance of promoting a variety of cognitive, academic and behavioural skills to enhance later achievement in at-risk learners.

\section{Introduction}

For every individual child, kindergarten is meant to consolidate early academic, learning and intellectual skills in order to benefit subsequent, more challenging learning experiences from first grade onwards (Zuckerman \& Halfon 2003). Children show different strengths and weaknesses at school entry. Some are strong on intellectual skills while others are less able (Duncan et al. 2007). Similarly, some have a more dedicated work ethic and others are less engaged towards task completion and academic activities in the classroom (High \& the Committee on Early Childhood, Adoption, and Dependent Care and Council on School Health 2008). Helping instructors identify which children are at risk of experiencing academic difficulty can help prevent later academic adjustment problems. The purpose of the present study is therefore to describe different student profiles of readiness and to examine how these profiles forecast later achievement.

What kinds of skills are desirable in young learners? General intelligence is a very good predictor of academic achievement, successful and gainful employment, career potential and higher lifestyle quality (Colom \& Flores-Mendoza 2007; Deary et al. 2007; Der, Batty \& Deary 2009; Duncan et al. 2007; Kuncel, Hezlett \& Ones 2004; Romano et al. 2010). Recent evidence also suggests that intellectual skills may be more important than non-cognitive skills, such as motivation, for academic achievement (Lu et al. 2011). There is empirical evidence to suggest that intelligence begins to crystallise around the time of school entry and then remains relatively stable through late adulthood (Deary et al. 2012). Furthermore, standardised assessments of intellectual ability remain common for screening and identifying kindergarten students with potential learning problems or exceptional ability.

In addition to general intelligence, children also need knowledge-based intellectual skills in mathematics and language to help them acquire increasingly complex lessons (Westerveld et al. 2015). Several large-scale studies have shown that receptive vocabulary and number knowledge are highly predictive of subsequent achievement (Duncan et al. 2007; Pagani et al. 2010; Romano et al. 2010). Furthermore, these skills appear to predict achievement regardless of gender, the types of homes children come from or family income.

Finally, researchers are increasingly aware that learning draws upon a number of competencies in addition to intellectual skills typically measured by standardised tests (Duckworth et al. 2007; Duckworth \& Seligman 2005; McClelland, Acock \& Morrison 2006). School entry is the first time

Note: This article is based on the authors postdoctoral paper: http://www.frqsc.gouv.qc.ca/documents/11326/552404/PT_FitzpatrickC_ rapport_primaire.pdf/943cb66a-3d73-4408-b918-9a00a258152a 
children encounter expectations regarding time limits for accomplishing tasks and adhering to an agenda. Furthermore, as early as kindergarten, children must learn to focus their energies on teacher-directed activities, delay gratification and follow formal and informal rules in the classroom setting (McDermott, Mordell \& Stoltzfus 2001; Mischel, Shoda \& Rodriguez 1989). When asked about which characteristics they favoured in young students, elementary school teachers tend to indicate child ability to self-regulate, pay attention and effectively manage behaviours (Rimm-Kaufman et al. 2002). Consequently, how teachable young children are in the classroom is likely to play an important role in early academic adjustment. For this reason, a person-environmentfit perspective predicts that productive behaviour and the capacity to adapt to classroom demands is likely to support successful child transitions into formal schooling regardless of intellectual ability and knowledge-based skills (Alexander, Entwisle \& Dauber 1993; Bowles, Gintis \& Osborne 2001; Fantuzzo et al. 2007; Li-Grining et al. 2010; McWayne, Fantuzzo \& McDermott 2004; Skinner, Kindermann \& Furrer 2009).

Classroom engagement represents a reflection of productive behaviour and of person-environment-fit in the school context. A child that is engaged in the classroom is attentive to teacher directions, displays cooperation and completes work independently and on time. When actively applied by students, such behaviours set the stage for short- and longterm academic and personal success (Cunha et al. 2005; DiPrete \& Eirich 2006; Fitzpatrick \& Pagani 2013). Classroom engagement also falls under the broader category of learningrelated behaviours which are likely to be partially driven by self-regulatory skills (Rimm-Kaufman et al. 2009; Sasser, Bierman \& Heinrichs 2015). Self-regulation comprises a combination of cognitive and emotional strategies individuals use to influence their own internal states, thoughts and behaviours. As such, self-regulation is likely to support classroom engagement behaviour by facilitating effortful control, delay of gratification and self-control.

There is evidence that early language, mathematical and intellectual and classroom engagement skills represent important components of kindergarten readiness. However, little research to date has examined whether it is possible to describe different types of learners based on these dimensions. The majority of school readiness studies have employed variable-based analytic approaches, which estimate the relative contributions of individual school readiness indicators to academic outcomes. This approach is useful for identifying significant predictors of achievement. However, such variable-based approaches assume that children are a homogenous group, or that relationships between variables are the same for all children. Variable-centred approaches also preclude the existence of subgroups of children that may differ in their profiles of school readiness. One exception is a study by Sabol and Pianta (2012) who used a person-centred approach to detect five preschool profiles on the basis of child emotional and cognitive control. The authors then examined how profile membership predicted achievement in the fifth grade. Although research using variable-centred approaches have generally concluded that socioemotional skills are nonsignificant predictors of later achievement (Duncan et al. 2007), a recent study using a person-centred approach has found that socioemotional skills predict academic success when they are present in students with poor cognitive control (Denham et al. 2012). This finding highlights the potential usefulness of applying person-centred approaches which are better suited for taking into account multiple and correlated characteristics of children.

The present study draws upon a population-based longitudinal sample of French-Canadian children. A first objective is to employ a person-centred approach to examine whether student risk profiles can be identified in kindergarten on the basis of child school readiness characteristics. A second objective is to estimate whether kindergarten student profiles differentially predict achievement outcomes by the end of the fourth grade. We expect that kindergarten students showing higher levels of risk in terms of their intellectual, academic and engagement skills will perform worse academically four years later.

Several child and family demographic factors may influence both child school entry competence and later academic outcomes. Children who are chronologically older at school entry may be better prepared and maintain an advantage relative to younger classmates. Girls also tend to be better prepared at school entry than boys and tend to show less disruptive classroom behaviour (Duncan et al. 2007). Children who grow up in poverty also face a constellation of family and environmental risk factors that undermine school readiness (Duncan \& Brooks-Gunn 1997; Noble, Norman \& Farah 2005). Finally, problematic behavioural characteristics such as presenting high levels of hyperactivity, physical aggression or emotional distress can interfere with learning behaviour in the classroom and thus undermine child academic achievement (Chen et al. 2010; Pagani et al. 2001). Inversely, prosocial skills predict improvements in academic performance (Ladd, Birch \& Buhs 1999). As such, the present study includes measures of child sex and age, socioeconomic status and family background characteristics and behavioural adjustment as control variables.

\section{Method Participants}

Participants are drawn from the Quebec Longitudinal Study of Child Development (QLSCD, 1998-2017), coordinated by the Quebec Institute of Statistics. The QLSCD is a randomly selected, stratified sample of 2694 infants born between 1997 and 1998 in Quebec, Canada. The sample was followed up on an annual basis from 5 to 98 months and every 2 years from 98 months onwards. Among the 2694 children, some were deemed ineligible or untraceable, which reduced the eligible follow-up sample to 2120 infants from the first wave onwards. Children had to be 60 months on September 30 to be eligible for kindergarten entry in fall of 2002. Data on early academic and intellectual skills were individually assessed at 
the end of kindergarten for 1145 children. Classroom engagement was also measured at the end of the school year by teacher reports. The mean age of children at the end of kindergarten was 73.68 months. Boys represented $46 \%$ of the sample. Some teachers did not provide child classroom engagement data, which reduced our analytic sample to 670 cases. Follow-up occurred in the fourth grade (mean age $=120$ months, $46 \%$ male) .

\section{Data collection procedures}

From school entry onwards, data collection occurred in the spring. Families, teachers and school principals received informed consent forms by mail. Teachers and families also received and returned questionnaires by mail. Parents were interviewed by trained research assistants by phone or in person. Parents were compensated an amount of $\$ 25$ and were informed that their child would receive a small gift. Direct assessments were mostly done at school. When unable to be evaluated at school, some children were evaluated at home.

\section{Measures: Predictors - School readiness indicators (at 74 months)}

\section{Intellectual skills}

Trained examiners administered the Block Design subtest of the Wechsler Preschool and Primary Scale of IntelligenceRevised to assess fluid intellectual skills (WPPSI-R, Wechsler 1991). This subtest assesses visual perception of the spatial relationships of objects and correlates well with general IQ (Sattler 2008). Children reproduced 14 models using blocks. For the first six models, children received 2 points for every model correctly reproduced within the time allotted (30 s). Children were given 1 point if they correctly produced the design on the second trial. Children received 0 points if they failed to reproduce the design in time on trial 1 or 2 . On the last seven models, children received only one trial. Two points were provided for each correct answer reproduced in time.

\section{Early academic skills}

The Number Knowledge Test (NKT) was administered to assess basic knowledge of numbers (Okamoto \& Case 1996). The version adjusted for 5-year-olds measures knowledge of the number sequence from 1 to 10, knowledge of the one-toone correspondence in which a sequence is mapped onto objects being counted, understanding the cardinal value of each number, understanding the generative rule which relates adjacent cardinal values and understanding that each successive number represents a set which contains more objects. Children also completed the most recent version of the Peabody Picture Vocabulary Test (PPVT, Dunn, ThériaultWhalen \& Dunn 1993) to assess vocabulary knowledge. This test consists of 175 vocabulary items that increase in difficulty throughout the test. Its French translation has been standardised and is highly correlated with other French vocabulary and intelligence tests.

\section{Classroom engagement}

Kindergarten teachers rated items pertaining to productive behaviour in the classroom. A mean classroom engagement score was computed for each participant from seven items: works neatly and carefully; follows rules and instructions; follows directions; listens attentively; completes work on time; works autonomously; and works and plays cooperatively with other children, $\alpha=0.92$. Each item was rated on a scale from 1 (never) to 3 (always). The classroom engagement scale has shown good predictive and construct validity (Fitzpatrick \& Pagani 2013; Pagani et al. 2010). Confirmatory factor analysis was conducted to examine how well our seven-item classroom engagement scale can be accounted for by a single factor. Model fit was good, suggesting the items capture a single latent factor $(\mathrm{CFI}=0.98$; $\mathrm{TLI}=0.97$; RMSEA $=0.069 ;$ SRMR $=0.034$ ).

\section{Measure outcomes: Academic achievement (120 months)}

Mathematical achievement was assessed using the Canadian Achievement Test (CAT/2) which children completed with a trained examiner at the end of the fourth grade. This test evaluates mastery of four basic mathematical operations: addition, subtraction, multiplication and division. Each question requires the application of basic operations to whole numbers. Children received one point for each correct answer. The sum of correct answers was used in the analyses.

Fourth-grade teachers rated child mathematical, reading, science, spelling and global achievement relative to their classmates by choosing among the following options: near the top of the class (scored as 2); above the middle of the class (scored as 1); in the middle of the class (scored as 0 ); below the middle of the class (scored as -1 ); or near the bottom of the class (scored as -2). This outcome measure has been found to be as sensitive and robust as individual achievement tests in detecting even subtle changes in academic performance over time (Duncan et al. 2007).

\section{Measures: Control variables}

\section{Child characteristics}

These include child sex, age in months and kindergarten teacher reports of child behavioural characteristics using the Social Behaviours Questionnaire (Pagani et al. 2001). Behavioural factors include hyperactive (cannot sit still; is restless and hyperactive; and cannot stop fidgeting; $\alpha=0.88$ ); emotional distress (seems unhappy or sad; is not as happy as other children; has no energy; is feeling tired; cries a lot; has trouble enjoying himself or herself; and is unable to make decisions; $\alpha=0.79$ ); and prosocial skills (tries to help someone who has been hurt; comforts a child who was crying or upset; and helps other children who were feeling sick; $\alpha=0.85$ ). Scores were rated on a Likert scale from 1 (often or very true) to 3 (never or not true). Each child's mean was then converted to a continuous score ranging from 0 to 10 . 


\section{Family characteristics}

When children were 5 and 17 months, parents reported on some child context variables, including: (1) family functioning ('planning activities is difficult because we misunderstand each other' or 'we avoid discussing our fears or concerns'), coded from 1 (strongly agree) to 4 (strongly disagree) and rescaled as a continuous score from 1 to 10 (Epstein, Baldwin \& Bishop 1983); (2) family configuration (intact $=0$ vs nonintact $=1$ ); and (3) socioeconomic status based on parental education, occupation and income. In addition, in order to rule out parental non-conformism and unconventionality, history of antisocial behaviour in mothers and fathers was assessed by self-report with parents at the five-month assessment. The items assessed the extent to which parents had engaged in antisocial behaviour during adolescence and adulthood and were derived from the NIMH-Diagnostic Interview Schedule. Adolescent items include: starting fights; theft; involvement with youth protection or police; expulsion or suspension from school; truancy; and running away from home. Adult items include: arrests; being fired from a job; trouble at work, with family or with the police because of drug or alcohol abuse; starting fights (fathers only); and hitting or throwing things at the spouse or partner (mothers only). Each item was scored as 1 (yes) and 0 (no) and was summed for each parent. Because scores were severely skewed, parents who received a score above the 70th percentile were given a score of 1 and those beneath the 70th percentile were given a score of 0 . Antisocial scores reflect the sum of dichotomous scores for each parent.

\section{Data analytic strategy}

We used latent class analysis (LCA) to detect distinct child profiles which differ in school readiness, based on: (1) general intellectual skills; (2) knowledge-based skills (receptive vocabulary and number knowledge); and (3) classroom engagement. LCA was conducted with MPLUS 5.1. LCA provides classification of individuals based on the relationships among variables. The results of LCA also provide estimated conditional means for continuous level variables (i.e. intellectual skills) and probabilities for each response category of categorical level variables (i.e. classroom engagement), based on class membership. The measure of children's classroom engagement was positively skewed and violated distributional assumptions of normality necessary for the treatment of continuous level variables in LCA. It was thus transformed into a three category ordinal variable reflecting low $(25.5 \%)$, medium $(35.9 \%)$ and high classroom engagement (38.7\%), respectively. Maximum likelihood estimation method with robust standard errors and random starting values were used to estimate classes. Observed variables were constrained to be uncorrelated within each class (Muthén \& Muthén 2012).

Following LCA, our objective is to estimate whether kindergarten readiness profiles predict fourth-grade academic adjustment. Using multiple regression, we first entered all the control variables in a single step. We then entered kindergarten profile membership in a second step to examine how kindergarten profiles contribute to fourthgrade academic adjustment beyond the control variables.

\section{Results Incomplete data}

As in most longitudinal large-scale studies, some participants had incomplete data on one or more variables. Attrition occurred for $31 \%$ of our sample on fourth-grade teacher reports of mathematical, reading, writing, science and global achievement. For the direct assessment of fourth-grade mathematical achievement, data were incomplete for $14 \%$ of our sample.

Because incomplete data could be predicted by covariates included in our sample, it was reasonable to assume that the data were missing at random (Cummings 2013; Schafer 1999). In order to reduce bias because of differential attrition, we conducted multiple imputation using NORM software on outcome and control variables. Attrition on predictor variables was not imputed. By drawing values from the conditional distribution of the variables, NORM uses an iterative method based on an expectation-maximisation algorithm to impute missing data (Cummings 2013; Schafer 1999). This approach is statistically powerful yet conservative and is considered among the best practices in dealing with sample attrition (Graham 2009; Worthke 2000). Data were imputed taking into account the variables in the overall data analytic strategy. Each data set was replaced by merging 100 estimated imputed data sets and taking into account standard error across and within data sets.

\section{Latent class analyses}

Descriptive statistics for the independent, dependent and control variables are reported in Table 1. To answer our first research question, we conducted LCA to identify profiles of

TABLE 1: Descriptive table for independent, dependent and control variables.

\begin{tabular}{lccc}
\hline Variables & $M($ SD $)$ & Min & Max \\
\hline Kindergarten school readiness characteristics (74 months) & & \\
Classroom engagement & $2.69(0.38)$ & 1.57 & 3.00 \\
Receptive vocabulary & $80.57(17.00)$ & 15.00 & 30.00 \\
Number knowledge & $13.25(3.27)$ & 3.00 & 18.00 \\
Non-verbal IQ & $19.95(9.80)$ & 2.00 & 50.00 \\
Fourth-grade achievement (120 months) & & & \\
Reading & $0.41(1.29)$ & -3.00 & 3.00 \\
Writing & $0.26(1.33)$ & -4.00 & 4.00 \\
Mathematics & $0.54(1.23)$ & -3.00 & 4.00 \\
Science & $0.55(1.03)$ & -2.00 & 3.00 \\
Global achievement & $0.93(0.80)$ & -1.00 & 3.00 \\
Mathematics (direct assessment) & $14.88(3.38)$ & 0.00 & 22.00 \\
Child and family control variables & & & \\
Hyperactivity (74 months) & $1.96(2.41)$ & 0.00 & 10.00 \\
Emotional distress (74 months) & $1.70(1.66)$ & -1.17 & 8.33 \\
Physical aggression (74 months) & $0.96(2.09)$ & 0.00 & 10.00 \\
Prosocial behaviour (74 months) & $5.29(2.59)$ & -2.47 & 10.67 \\
Age of the child & $73.68(3.05)$ & 68.6 & 80.90 \\
Sex (1 = boy, 0 = girl) & $0.46(0.50)$ & 0.00 & 1.00 \\
Socioeconomic status & $0.01(0.76)$ & -2.00 & 3.00 \\
Parental antisocial behaviour (5 months) & $0.64(0.69)$ & 0.00 & 2.00 \\
Family configuration (17 months) & $0.12(0.32)$ & 0.00 & 1.00 \\
Family functioning (5-17 months) & $1.22(1.27)$ & -0.16 & 8.15 \\
\hline
\end{tabular}

SD, standard deviation. 
child school readiness. Results favoured a three class solution (see Table 2). Although the Likelihood Ratio Test suggested no significant difference between a three and four class solution, there was a slight BIC decrease with a four class solution. To favour a more parsimonious model, we therefore opted for a three group model. The majority of children showed an adaptive profile kindergarten readiness characterised by high levels of intellectual, knowledge-based and classroom engagement skills (56.7\%). A second profile, representing $34 \%$ of the children, showed a pattern of moderate readiness. This group was characterised by moderate engagement and number knowledge and low levels of receptive vocabulary. Finally, 9.3\% of children showed a pattern of low readiness characterised by the lowest levels of all kindergarten skills. This group did not differ significantly from the moderate group on intellectual and language skills.

We used one-way analysis of variance to examine whether the profiles differed significantly on school readiness indicators. There were significant group differences on intellectual skills $[F(2667)=107.27, p<0.0001]$, receptive vocabulary $[F(2667)=139.03, p<0.0001]$, number knowledge $[F(2667)=1223.12, p<0.0001]$, and classroom engagement $[F(2667)=63.91, p<0.0001]$. We conducted post hoc analyses using Bonferoni corrections to identify where the group differences were. Analyses revealed that the children in the adaptive group outperformed the children in the two other readiness groups on intellectual skills ( $\bar{x}=23.67$ vs 12.83 and 14.24 , respectively), receptive vocabulary $(\bar{x}=88.43$ vs 66.56 and 70.88 , respectively) and number knowledge ( $\bar{x}=15.38$ vs 5.95 and 11.61, respectively). They were also more engaged in the classroom ( $\bar{x}=2.80$ vs 2.39 and 2.56 , respectively). We then compared the moderate and high risk groups.

TABLE 2: Fit indices and entropy for different class solutions.

\begin{tabular}{lccc}
\hline Classes & BIC & $\begin{array}{c}\text { Vuong-Lo-Mendell-Rubin } \\
\text { Likelihood ratio test }\end{array}$ & Entropy \\
\hline Two classes & 21110.17 & $-10745.36 * * *$ & 0.76 \\
Three classes & 21011.25 & $-10507.29 * * *$ & 0.75 \\
Four classes & 21008.19 & -10437.35 & 0.75 \\
Five classes & 20999.76 & -10415.38 & 0.72 \\
\hline
\end{tabular}

BIC, Bayesian information criterion.

$* * * p<0.001$.
The moderate risk group scored higher than the high risk group on number knowledge ( $\bar{x}=11.61$ vs 5.95 ) and classroom engagement $(\bar{x}=2.56$ vs 2.39$)$. The moderate and low readiness profiles did not differ significantly in intellectual skills or receptive vocabulary.

\section{Multiple regression}

We first entered all control variables in the regression equation in a single step. We then entered kindergarten profile membership in a second step to examine how kindergarten profiles contributed to the outcomes beyond the control variables. Regression coefficients for the associations between kindergarten readiness profiles and fourth-grade academic outcomes are reported in Table 3. The addition of kindergarten readiness profiles contributed a significant proportion of variance for each of the estimated models. More specifically, the inclusion of kindergarten readiness profiles accounted for an additional 11.3\% and $8.8 \%$ of the variance in fourth-grade teacher-rated reading and writing, respectively; an additional $12.3 \%, 7.7 \%$, and $7.8 \%$ of the variance in teacher-rated math, science, and global achievement; and $10.2 \%$ of directly assessed math performance.

For each regression, we compare the group showing the most adaptive pattern of kindergarten readiness to the two at-risk groups. Compared to children showing adaptive school readiness, children in the highest risk group scored worse on fourth-grade teacher-rated reading $(\beta=-1.37, p<0.001)$, writing $(\beta=-1.26, p<0.001)$, mathematics $(\beta=-1.45, p<$ $0.001)$, science $(\beta=-0.90, p<0.001)$ and global achievement $(\beta=-0.72, p<0.001)$. They also performed worse on directly assessed mathematics $(\beta=-4.07, p<0.001)$. Children showing the most adaptive pattern of school readiness also performed better than the moderate risk group on all the academic measures. Compared to the adaptive group, the moderate risk group scored lower on fourth-grade teacher-rated reading $(\beta=-0.80, p<0.001)$, writing $(\beta=-0.71, p<0.001)$, mathematics $(\beta=-0.75, p<0.001)$, science $(\beta=-0.38, p<0.001)$, global achievement $(\beta=-0.40, p<0.001)$ and directly assessed mathematics ability $(\beta=-0.98, p<0.001)$.

TABLE 3: Unstandardised regression coefficients reporting the relationship between kindergarten school readiness profile membership and fourth-grade academic adjustment.

\begin{tabular}{|c|c|c|c|c|c|c|}
\hline \multirow[t]{2}{*}{ Predictors } & \multicolumn{5}{|c|}{ Teacher-rated achievement } & \multirow{2}{*}{$\begin{array}{c}\text { Direct assessment } \\
\text { mathematics }\end{array}$} \\
\hline & Reading & Writing & mathematics & Science & Global & \\
\hline Moderate readiness & $-0.80(0.10) * * *$ & $-0.71(0.10) * * *$ & $-0.75(0.10)^{* * *}$ & $-0.38(0.09) * * *$ & $-0.40(0.07)^{* * *}$ & $-0.98(0.27)^{* * *}$ \\
\hline Low readiness & $-1.37(0.17) * * *$ & $-1.26(0.17)^{* * *}$ & $-1.45(0.16)^{* * *}$ & $-0.90(0.14)^{* * *}$ & $-0.72(0.11)^{* * *}$ & $-4.07(0.43)^{* * *}$ \\
\hline Hyperactive behaviour & $-0.06(0.02)^{*}$ & $-0.09(0.02) * * *$ & $-0.07(0.02)^{* *}$ & $-0.03(0.02)$ & $-0.04(0.02)^{*}$ & $-0.14(0.60)^{*}$ \\
\hline Emotional distress & $-0.07(0.03)^{*}$ & $-0.13(0.03) * * *$ & $-0.08(0.03) * *$ & $-0.06(0.02)^{*}$ & $-0.06(0.02)^{* *}$ & $-0.14(0.08)$ \\
\hline Physical aggression & $0.01(0.03)$ & $0.01(0.03)$ & $-0.01(0.03)$ & $-0.02(0.02)$ & $0.02(0.02)$ & $0.02(0.07)$ \\
\hline Prosocial skills & $0.04(0.04)$ & $0.00(0.02)$ & $0.00(0.02)$ & $0.00(0.02)$ & $0.00(0.01)$ & $0.05(0.05)$ \\
\hline Family functioning & $-0.01(0.04)$ & $-0.07(0.04)$ & $-0.09(0.03)^{* *}$ & $-0.05(0.03)$ & $0.05(0.04)^{*}$ & $0.00(0.09)$ \\
\hline Family configuration & $0.01(0.14)$ & $-0.08(0.14)$ & $-0.08(0.13)$ & $-0.09(0.12)$ & $-0.07(0.09)$ & $-1.30(0.37)^{* *}$ \\
\hline Parent antisocial behaviour & $-0.07(0.07)$ & $-0.06(0.07)$ & $0.01(0.06)$ & $-0.07(0.05)$ & $0.03(0.04)$ & $0.01(0.17)$ \\
\hline Socioeconomic status & $-0.01(0.07)$ & $-0.03(0.07)$ & $-0.02(0.06)$ & $-0.05(0.05)$ & $0.03(0.04)$ & $0.47(0.17)^{* *}$ \\
\hline$R^{2}$ & 0.19 & 0.21 & 0.22 & 0.13 & 0.13 & 0.21 \\
\hline
\end{tabular}

Note: The adaptive readiness profile serves as the omitted category. Models are adjusted for child sex and kindergarten age in months.

${ }^{*} p<0.05, * * p<0.01, * * * p<0.001$. 


\section{Discussion}

The first goal of this study was to examine whether children show different profiles of school readiness. We found three types of kindergarten students that differed on the basis of their academic, intellectual and classroom engagement skills. The majority of children in our population-based sample (57\%) showed an adaptive pattern of school readiness, characterised by high scores on all of the kindergarten skills. Nevertheless, a substantial proportion of children (43\%) appeared less than optimally prepared to learn and demonstrated less than optimal levels of school readiness. Although both of these groups showed low levels of receptive vocabulary and fluid intelligence, the moderate risk group scored higher on kindergarten number knowledge and classroom engagement. To our knowledge, this study is the first to identify two at-risk profiles of kindergarten children based on knowledge-based, intellectual and classroom engagement skills.

Children showing moderate and low levels of readiness differed in measurable ways on classroom engagement and mathematics skills. The relationship between kindergarten number knowledge and classroom engagement observed in our study is consistent with previous research linking both skills to effective cognitive control (Blair \& Razza 2007; Fitzpatrick \& Pagani 2013). In the classroom, children with poor levels of cognitive control have a harder time sitting still, following sequential instructions, managing time and keeping their desks neat (Fitzpatrick \& Pagani 2012). Furthermore, cognitive control also partially explains early mathematical ability and child reasoning skills through attention, working memory and inhibitory control mechanisms (Blair \& Razza 2007).

Kindergarten receptive vocabulary and fluid intelligence appeared to be less closely related to mathematical ability and classroom engagement in our profiles. This may have been the case because receptive vocabulary and fluid intelligence are distinct from cognitive control and may be more highly related to general intelligence or socioeconomic status. Although important for academic achievement, general intelligence may be more resistant to intervention. Consequently, it may be especially efficient to target cognitive control as a means of promoting both classroom engagement and math achievement in at-risk kindergarten students.

The second aim of our study was to examine whether school readiness profiles are prospectively associated with subsequent academic achievement. We compared children with the most adaptive pattern of school readiness to two groups of children showing lower levels of school readiness. Compared to children showing the most adaptive school readiness profile, children in the low and moderate readiness groups had poorer outcomes in the fourth grade. Belonging to the moderate readiness group, characterised by better mathematical and classroom engagement skills, also predicted a significant long-term advantage when compared to children showing the lowest levels of school readiness. Both the moderate and low readiness classes of children had lower levels of intellectual and language skills. Consequently, our findings provide some evidence that in the absence of these skills, adequate classroom engagement and mathematical skills may represent a protective factor in the classroom. These findings provide a more detailed understanding of school readiness and expand on previous research which has mainly used variable-centred approaches to explain the relative importance of school readiness characteristics (Duncan et al. 2007; Pagani et al. 2010).

The findings from this study advance our knowledge of school readiness by suggesting that a combination of productive classroom behaviours reflecting conscious effort and task-orientation, in addition to academic and intellectual skills, may give young students the strongest foundation for later achievement. Children belonging to the lowest readiness group showed the greatest difficulty in both teacher and directly assessed mathematics. This is not surprising as these children also showed the lowest level of early mathematics knowledge. Interestingly, children in this group, which did not differ significantly from the moderate risk group in terms of early language and intellectual skills, also experienced the most difficulty in reading and writing by the fourth grade. Consequently, these results suggest a role for early mathematical and classroom engagement in predicting later verbal performance. Fourth-grade achievement in reading involves highly automatic letter and phoneme identification processes which are knowledge based and are reinforced by opportunities for literacy found outside the formal schooling environment (Hart \& Risley 1995). Nevertheless, reading achievement also requires effective reasoning skills, learning strategies and cognitive control (Altemeier, Abbott \& Berninger 2008). Inhibitory control, which is a main component of cognitive control strategies, has been found to play a significant role in the acquisition of letter identification automaticity and phonemic awareness (Blair \& Razza 2007). Furthermore, writing and its components in terms of composition, spelling and punctuation represent a problem-solving process driven by planning, translating and reviewing material being produced for communication purposes (Altemeier et al. 2006). Finally, learning in other academic realms such as science also depends on similar sets of skills because it requires similar memorisation and reasoning strategies.

Our findings suggest the potential benefit of targeting classroom engagement and number knowledge with children showing low levels of kindergarten readiness. Classroom engagement skills, in particular, can be routinely and costeffectively monitored and assessed by elementary school teachers during instructional activities (Lee \& Reeve 2012). More importantly, classroom engagement skills represent malleable behaviours that can be targeted through preschool intervention or shaped, reinforced, and modelled by classroom teachers (Fredricks, Blumenfeld \& Paris 2004). Finally, the identification of different profiles of child readiness in our large population-based sample may benefit the development of more tailored and refined kindergarten interventions. 
A promising avenue for increasing both number knowledge and classroom engagement involves strengthening child cognitive control. The development of interventions that strategically combine computerised training, classroom instruction and curriculum, aerobic exercise, mindfulness training, and martial arts, tailored to suit the needs of different learners, are likely to be especially effective in promoting classroom engagement and mathematical skills (Bierman et al. 2008; Diamond et al. 2007; Flook et al. 2010; Kamijo et al. 2011; Klingberg et al. 2005; Klingberg, Forssberg \& Westerberg 2002; Lakes \& Hoyt 2004; Lillard \& Else-Quest 2006). Children showing initially higher levels of academic risk, such as children from disadvantaged families, boys and children with ADHD, have also been found to benefit the most from cognitive control training (Diamond \& Lee 2011). Targeting these skills therefore appears to be a promising strategy for equalising inequalities in achievement.

Our findings should be interpreted in the context of certain limitations. First, although prospective, our results are based on a correlational study of development occurring in a natural context. As a result, despite our attempt to methodologically reduce the competing influence of several child and family confounding variables, it is not possible to infer a causal relationship between our independent and dependent variables. In this study, we preferred to adopt a person-centred approach to observe how features of school readiness co-occur in a population. As a result, this method prevents us from identifying precisely which features of school readiness make a stronger overall contribution to later achievement. Nevertheless, the results of other longitudinal studies of school readiness with the same sample provide evidence that both classroom engagement and intellectual skills measured in kindergarten represent robust and independent predictors of later achievement (Fitzpatrick \& Pagani 2013; Pagani et al. 2010).

The possibility of early detection and intervention with children at risk of learning difficulties represents our most promising strategy for circumventing a number of expensive social problems which are associated with high school dropout, such as unemployment, substance abuse and involvement in crime (Cunha et al. 2005; Shonkoff 2011). Although it is common to screen for intellectual skills and early academic skills at school entry, classroom engagement skills are not routinely assessed. These behaviours can be easily recorded and monitored by regular classroom teachers as an alternative to more expensive screening often conducted by professionals using universal, inexpensive and ecological assessments. Policies concerned with school readiness could be ameliorated by incorporating strategies aimed at helping teachers assess and reinforce engagement behaviour and mathematical skills in the kindergarten classroom. The prospective associations found in this longitudinal study speak directly to preventive practices in contexts concerned with learning and instruction. They also support the need for preschool interventions and early screening procedures which involve knowledge-based, intellectual and learning-related skills.

\section{Acknowledgements Competing interests}

The author declares that she has no financial or personal relationships which may have inappropriately influenced her in writing this article.

\section{References}

Alexander, K.L., Entwisle, D.R. \& Dauber, S.L., 1993, 'First-grade classroom behavior: Its short-and long-term consequences for school performance', Child Development 64, 801-814.

Altemeier, L., Abbott, R. \& Berninger, V., 2008, 'Executive functions for reading and writing in typical literacy development and dyslexia', Journal of Clinical and Experimental Neuropsychology 30, 588-606.

Altemeier, L., Jones, J., Abbott, R. \& Berninger, V., 2006, 'Executive functions in becoming writing readers and reading writers: Note taking and report writing in third and fifth graders', Developmental Neuropsychology 29, 161-173.

Bierman, K.L., Domitrovich, C.E., Nix, R.L., Gest, S.D., Welsh, J.A., Greenberg, M.T. et al., 2008, 'Promoting academic and social-emotional school readiness: The Head Start REDI program', Child Development 79, 1802-1817.

Blair, C. \& Razza, R., 2007, 'Relating effortful control, executive function, and false belief understanding to emerging math and literacy ability in kindergarten', Child Development 78, 647-663.

Bowles, S., Gintis, H. \& Osborne, M., 2001, 'The determinants of earnings: A behavioral approach', Journal of Economic Literature 39, 1137-1176.

Chen, X., Huang, X., Chang, L., Wang, L. \& Li, D., 2010, 'Aggression, social competence, and academic achievement in Chinese children: A 5-year longitudinal study', Development and Psychopathology 22, 583-592.

Colom, R. \& Flores-Mendoza, C.E., 2007, 'Intelligence predicts scholastic achievement irrespective of SES factors: Evidence from Brazil', Intelligence 35, 243-251.

Cummings, P., 2013, 'Missing data and multiple imputation', JAMA Pediatrics 167, 656-661.

Cunha, F., Heckman, J.J., Lochner, L. \& Masterov, D., 2005, Interpreting the evidence on life cycle skill formation, viewed 5 June, 2016 from http://www.nber.org/papers/ w11331.pdf

Deary, I.J., Strand, S., Smith, P. \& Fernandes, C., 2007, 'Intelligence and educational achievement', Intelligence $35,13-21$.

Deary, I.J., Yang, J., Davies, G., Harris, S.E., Tenesa, A., Liewald, D. et al., 2012, 'Genetic contributions to stability and change in intelligence from childhood to old age', Nature 482, 212-215.

Denham, S.A., Basset, H., Mincic, M., Kalb, S., Way, E., Wyatt, T. et al., 2012, 'Socialemotional learning profiles of preschoolers' early school success: A personcentered approach', Learning and Instruction 22, 178-189.

Der, G., Batty, G.D. \& Deary, I.J., 2009, 'The association between IQ in adolescence and a range of health outcomes at 40 in the 1979 US National Longitudinal Study of Youth', Intelligence 37, 573-580.

Diamond, A., Barnett, W.S., Thomas, J. \& Munro, S., 2007, 'Preschool program improves cognitive control', Science 318, 1387-1388.

Diamond, A. \& Lee, K., 2011, 'Interventions shown to aid executive function development in children 4 to 12 years old', Science 333, 959-964.

DiPrete, T.A. \& Eirich, G.M., 2006, 'Cumulative advantage as a mechanism for inequality: A review of theoretical and empirical developments', American Sociological Review 71, 515-541.

Duckworth, A.L., Peterson, C., Matthews, M.D. \& Kelly, D.R., 2007, 'Grit: Perseverance and passion for long-term goals', Journal of Personality and Social Psychology 92 1087-1101.

Duckworth, A.L. \& Seligman, M.E.P., 2005, 'Self-discipline outdoes IQ in predicting academic performance of adolescents', Psychological Science 16, 939-944.

Duncan, G.J. \& Brooks-Gunn, J., 1997, Consequences of growing up poor, Russell Sage Foundation Publications, New York.

Duncan, G.J., Dowsett, C.J., Claessens, A., Magnuson, K., Huston, A.C., Klebanov, P. et al., 2007, 'School readiness and later achievement', Developmental Psychology $43,1428-1446$

Dunn, L.M., Theriault-Whalen, C.M. \& Dunn, L.M., 1993, Peabody picture vocabulary test-revised: French adaptation, Psycan, Toronto, ON.

Epstein, N.B., Baldwin, L.M. \& Bishop, D.S., 1983, 'The McMaster family assessment device', Journal of Marital and Family Therapy 9, 171-180.

Fantuzzo, J., Bulotsky-Shearer, R., McDermott, P., McWayne, C., Frye, D. \& Perlman, S. 2007, 'Investigation of dimensions of social-emotional classroom behavior and school readiness for low-income urban preschool children', School Psychology Review 36, 44-62.

Fitzpatrick, C. \& Pagani, L., 2012, 'Toddler working memory skills predict kindergarten school readiness', Intelligence 40, 205-212.

Fitzpatrick, C. \& Pagani, L.S., 2013, 'Task-oriented kindergarten behavior pays off in later childhood', Journal of Developmental \& Behavioral Pediatrics 34, 94-101.

Flook, L., Smalley, S.L., Kitil, M.J., Galla, B.M., Kaiser-Greenland, S., Locke, J. et al., 2010, 'Effects of mindful awareness practices on executive functions in elementary school children', Journal of Applied School Psychology 26, 70-95. 
Fredricks, J.A., Blumenfeld, P.C. \& Paris, A.H., 2004, 'School engagement: Potential of the concept, state of the evidence', Review of Educational Research 74, 59-109.

Graham, W.J., 2009, 'Missing data: Making it work in the real world', Annual Review of Psychology 60, 549-576.

Hart, B. \& Risley, T.R., 1995, Meaningful differences in the everyday experience of young American children, Brookes Publishing, Baltimore, MD.

High, P.C. \& The Committee on Early Childhood, Adoption, and Dependent Care and Council on School Health, 2008, 'School readiness', Pediatrics 121, 1008-1015.

Kamijo, K., Pontifex, M.B., O'Leary, K.C., Scudder, M.R., Wu, C.T., Castelli, D.M. et al., 2011, 'The effects of an afterschool physical activity program on working memory in preadolescent children', Developmental Science 14, 1046-1058.

Klingberg, T., Fernell, E., Olesen, P. J., Johnson, M., Gustafsson, P., Dahlström, K. et al., 2005, 'Computerized training of working memory in children with ADHD-a randomized, controlled trial', Journal of the American Academy of Child \& Adolescent Psychiatry 44, 177-186.

Klingberg, T., Forssberg, H. \& Westerberg, H., 2002, 'Training of working memory in children with ADHD', Journal of Clinical and Experimental Neuropsychology 24, 781-791.

Kuncel, N.R., Hezlett, S.A. \& Ones, D.S., 2004, 'Academic performance, career potential, creativity, and job performance: Can one construct predict them all?', Journal of Personality and Social Psychology 86, 148-161.

Ladd, G.W., Birch, S.H. \& Buhs, E.S., 1999, 'Children's social and scholastic lives in kindergarten: Related spheres of influence?', Child Development 70 , 1373-1400.

Lakes, K.D. \& Hoyt, W.T., 2004, 'Promoting self-regulation through school-based martial arts training', Journal of Applied Developmental Psychology 25, 283-302.

Lee, W. \& Reeve, J., 2012, 'Teachers' estimates of their students' motivation and engagement: Being in synch with students', Educational Psychology 32, 727-747.

Li-Grining, C.P., Votruba-Drzal, E., Maldonado-Carreño, C. \& Haas, K., 2010, 'Children's early approaches to learning and academic trajectories through fifth grade', Developmental Psychology 46, 1062-1077.

Lillard, A. \& Else-Quest, N., 2006, 'The early years: Evaluating Montessori education' Science 313, 1893-1894.

Lu, L., Weber, H.S., Spinath, F.M. \& Shi, J., 2011, 'Predicting school achievement from cognitive and non-cognitive variables in a Chinese sample of elementary school children', Intelligence 39(2), 130-140. https://doi.org/10.1016/j.intell.2011.02.002

McClelland, M.M., Acock, A.C. \& Morrison, F.J., 2006, 'The impact of kindergarten learning-related skills on academic trajectories at the end of elementary school', Early Childhood Research Quarterly 21, 471-490.

McDermott, P.A., Mordell, M. \& Stoltzfus, J.C., 2001, 'The organization of student performance in American schools: Discipline, motivation, verbal learning, nonverbal learning', Journal of Educational Psychology 93, 65-76.

McWayne, C.M., Fantuzzo, J.W. \& McDermott, P.A., 2004, 'Preschool competency in context: An investigation of the unique contribution of child competencies to early academic success', Developmental Psychology 40, 633-645.

Mischel, W., Shoda, Y. \& Rodriguez, M.L., 1989, 'Delay of gratification in children', Science 244, 933-938.

Muthén, L.K. \& Muthén, B.O., 2012, Mplus Version 7 user's guide, Muthén \& Muthén, Los Angeles, CA.
Noble, K.G., Norman, M.F. \& Farah, M.J., 2005, 'Neurocognitive correlates of socioeconomic status in kindergarten children', Developmental Science 8, 74-87.

Okamoto, Y. \& Case, R., 1996, 'Exploring the microstructure of children's central conceptual structures in the domain of number', Monographs of the Society for Research in Child Development 61, 27-58.

Pagani, L.S., Fitzpatrick, C., Archambault, I. \& Janosz, M., 2010, 'School readiness and later achievement: A French Canadian replication and extension', Developmental Psychology 46, 984-994.

Pagani, L.S., Tremblay, R.E., Vitaro, F., Boulerice, B. \& McDuff, P., 2001, 'Effects of grade retention on academic performance and behavioral development', Development and Psychopathology 13, 297-315.

Sasser, T.R., Bierman, K.L. \& Heinrichs, B., 2015, 'Executive functioning and school adjustment: The mediational role of pre-kindergarten learning-related behaviors', Early Childhood Research Quarterly 30, 70-79.

Rimm-Kaufman, S.E., Curby, TW., Grimm, K.J., Nathanson, L. \& Brock, L.L., 2009, 'The contribution of children's self-regulation and classroom quality to children's adaptive behaviors in the kindergarten classroom', Developmental Psychology 45(4), 958-972. https://doi.org/10.1037/a0015861

Rimm-Kaufman, S.E., Early, D.M., Cox, M.J., Saluja, G., Pianta, R.C., Bradley, R.H. et al., 2002, 'Early behavioral attributes and teachers' sensitivity as predictors of competent behavior in the kindergarten classroom', Journal of Applied competent behavior in the kinderga
Developmental Psychology 23, 451-470.

Romano, E., Babchishin, L., Pagani, L. \& Kohen, D., 2010, 'School readiness and later achievement: Replication and extension using a nationwide Canadian survey', Developmental Psychology 46, 995-1007.

Sabol, T.J. \& Pianta, R.C., 2012, 'Patterns of school readiness forecast achievement and socioemotional development at the end of elementary school', Child Development 83(1), 282-299. https://doi.org/10.1111/j.1467-8624.2011.01678.x

Sattler, J., 2008, The assessment of children: Cognitive foundations, 5th edn., Jerome Sattler Publications, La Mesa, CA.

Schafer, J.L., 1999, 'Multiple imputation: A primer', Statistical Methods in Medical Research 8, 3-15.

Shonkoff, J., 2011, 'Protecting brains, not simply stimulating minds', Science 333 , 982-983.

Skinner, E.A., Kindermann, T.A. \& Furrer, C.J., 2009, 'A motivational perspective on engagement and disaffection conceptualization and assessment of children's behavioral and emotional participation in academic activities in the classroom', Educational and Psychological Measurement 69, 493-525.

Wechsler, D., 1991, Wechsler intelligence scale for children, 3rd edn., The Psychological Corporation, San Antonio, TX.

Westerveld, M.F., Gillon, G.T., Van Bysterveldt, A.K. \& Boyd, L., 2015, 'The emergent literacy skills of four-year-old children receiving free kindergarten early childhood education in New Zealand', International Journal of Early Years Education 23, 339-351. https://doi.org/10.1080/09669760.2015.1033617

Worthke, W., 2000, 'Longitudinal and multigroup modeling with missing data', in T. Little, K. Schnabel \& J. Baumert (eds.), Modeling longitudinal and multilevel data: Practical issues, applied approaches, and specific examples, pp. 219-240, Erlbaum, Hillsdale, NJ.

Zuckerman, B. \& Halfon, N., 2003, 'School readiness: An idea whose time has come', Pediatrics 111, 1433-1435. 